\title{
REACTIVE ATTITUDES, RELATIONSHIPS, AND ADDICTION
}

\author{
Jeanette Kennett, Doug McConnell, and Anke Snoek
}

\section{Introduction}

What happens to close relationships of love and friendship in addiction? How does the impact of addiction on those relationships affect the addicted person's view of themselves and of their capacities for change and recovery? In this chapter, we focus on the structure of close personal relations and diagnose how these relationships are disrupted by addiction. We draw upon Peter Strawson's landmark paper 'Freedom and Resentment' (2008, first published 1962) to argue that loved ones of those with addiction veer between, (1) reactive attitudes of blame and resentment generated by disappointed expectations of goodwill and reciprocity, and (2) the detached objective stance from which the addicted person is seen as less blameworthy but also as less fit for ordinary interpersonal relationships. We examine how these responses, in turn, shape the addicted person's view of themselves, their character and their capacities, and provide a negative narrative trajectory that impedes recovery. We close with a consideration of how these effects might be mitigated by adopting less demanding variations of the participant stance.

\section{Psychological visibility, self-knowledge, and interpretation}

As social, embodied creatures we build our view of ourselves through physical and social interactions and through the interpretive practices that characterise different social relationships. Our interactions with inanimate physical objects, for example, can reveal and develop in us a variety of qualities, e.g. the strength to lift an object or the agility to climb over it. Our interactions with other animals, such as pets, who can respond to our intentions and attitudes go further than this by rendering us psychologically visible to ourselves, e.g. as threatening, playful, or affectionate - as possessing certain personal qualities, capacities and temperament (Branden 1993). Psychological visibility, however, is largely a function of our interactions with other human agents and the feedback that those interactions provide. Consider first the multitude of trivial and complex interactions that fill our day. We buy bus tickets, go through the supermarket checkout, greet colleagues, run meetings, ask for or provide directions, send texts, update our status on social media, order coffee. Through these interactions and the responses of others to us within them, we gain information both about what we are like and what is expected of us.

Much of this information is revealed via the other's range of emotional reactions to us: a yawn suggests I am boring, while a hurt expression might reveal that I was rude. Such responses may challenge or confirm the view we have of ourselves. I thought my joke was funny but others see it as lame. I thought I was being admirably blunt but I am coming across as rude and arrogant. Where there is a mismatch between the view we have of ourselves and the view we get through others eyes we might try to reconcile them in number of ways. I might modify my behaviour and responses so that you will see me the way I wish to be seen. Your raised eyebrow response to my miserly tip might trigger shame and prompt me to be more generous next time. In doing so, I bring my behaviour into line with the person I want to be, or at least with prevailing social norms. Alternatively, I might challenge or dismiss your interpretation of me. In one-off interactions perhaps this is easily done (she just can't take a joke) but, in interactions over time, a consistently negative response from others will be hard to ignore. Then I might internalise the 
other's view of me. If I come to see myself as clumsy in word or deed I will likely not attempt tasks that require finesse or dexterity. If I see myself as boring I may be less inclined to engage socially for fear of rejection. If I have a stigmatized social identity - e.g. that of an addict - the range of interactions available to me narrows and the negative feedback, even in casual interactions, becomes consistent. This also can have profound effects on my agency - my view of what I can do and how I can do it.

\section{The participant stance, the reactive attitudes, and effective agency}

Peter Strawson (2008) has pointed out the very great importance that we place on the attitudes of others in our interactions with them. In particular, Strawson focuses on a subset of our emotional reactions to each other that specifically communicate our moral expectations - the reactive attitudes. We expect people to act towards us with goodwill; when they do, we respond with gratitude and with forgiveness for unintentional harms. When they violate those expectations, we respond with resentment and hurt feelings. The reactive attitudes are, on this account, central to praise and blame. When we are prepared to expose others to the reactive attitudes we take what Strawson calls the 'participant stance' towards them.

Adults, he suggests, take the participant stance by default because they assume each other to be morally responsive and responsible agents capable of adjusting their behaviour and attitudes in the light of the demand for goodwill and the feedback on their behaviour provided within this stance. ${ }^{i}$ They must assume that is, that other has the set of agential capacities associated with autonomy, notably for moral understanding, self-reflection and self-control. The participant stance thus helps render the agent morally visible to herself as an equal moral agent and a member of the moral community and subject to mutual obligations within it. Specific instances of reactive attitudes help her to learn about her particular qualities that have a moral valence, such as degrees of generosity, trustworthiness, and consideration of others. Unexpected reactive attitudes, alert her to the fact that she has lost control of a moral aspect of her appearance. When the reactions of others are as the agent expects, they allow her to proceed with confidence because they indicate that she appears as she hoped to.

By contrast, we adopt what Strawson calls the 'objective stance' when the other's actions are consistently unmodified by our responses to them. We come to believe that they are incapable of ordinary adult relationships either because they lack the relevant agential capacities or refuse to exercise them. Strawson gives the example of the 'hopeless schizophrenic' $(2008,8)$, others include those with late stage dementia. When faced with such individuals, Strawson thinks we give up the disposition to resent or blame them for their harmful actions; we move, and should move, to the objective stance $(2008,9)$. From the objective stance, the other is seen as a problem "to be managed or handled or cured or trained; perhaps simply to be avoided" (2008, 10). The objective attitude may involve some emotions, such as repulsion, fear and pity, but not "the range of reactive feelings and attitudes which belong to involvement or participation with others in inter-personal human relationships" $(2008,10)$. However, Strawson also notes that we may also use the objective attitude as an escape from the strain of involvement with others $(2008,18)$. Certainly it is a stance that can characterise, in particular, professional interactions with groups such as delinquent adolescents, or, in the present case, people who are addicted. In these cases, the objective attitude is damaging insofar as it limits the kind of self-visibility available to those targeted by it. Those targeted may come to see themselves as things to be 
managed, handled, cured, trained, feared or pitied, rather than as capable and morally responsible agents.

\section{Close relationships - families and friends}

In normal circumstances, the effects of brief negative interactions in the public sphere on identity and sense of agency are outweighed by positive experiences in our more intimate relationships. Friends and family typically provide more charitable interpretations of the agent protecting her against rude shopkeepers, thoughtless co-workers, distant doctors or patronising social workers. My clumsiness might be interpreted to me as endearing rather than irritating; my labouring a point is seen by those who love me as indicative of an admirably deep concern about an issue rather than as pedantic and boring. Furthermore, friends and family know the agent's history and interact with her in various intimate situations so they can provide richer, more insightful, diachronic interpretations of the agent than others. ${ }^{\text {ii }}$ It is therefore not surprising that friends and family tend to shape the agent's self-concept more thoroughly than others do. Familial relationships and close friendships, however, contribute to our identities in different ways, and so these relationships are likely to be affected in somewhat different ways when one party develops an addiction.

We claim, following Cocking \& Kennett (1998) that close friendships are marked by a heightened mutual receptivity to our friends' ways of seeing us and to being directed by their interests. So, for example, I will typically be more open to activities that I have no antecedent interest in, such as going to the opera, if asked by my close friend than by my parents or a casual acquaintance. Similarly, we are more receptive to close friends' interpretations of us than those of mere acquaintances and our friend's interpretations and enthusiasms may encourage us to develop in new ways and strike out in new directions (e.g. "You have a great voice. You should join a choir"). Indeed, it is arguably an essential characteristic of close relationships that each remains responsive to a degree of shaping by the other. It is this characteristic of close friendship that explains the particularity and intimacy of friendship (Cocking and Kennett 1998). Conversely friendships become more distant and prone to the display of negative reactive attitudes to the extent that one or both participants feels that the other is insufficiently responsive to her interests and fixed in her interpretations. In such cases, the agent may feel that her friend no longer sees her.

By contrast, our identities within the family - who we are within the 'us' of the family is less open to mutual shaping by the participants. These identities are in significant part a function of shared history and propinquity and, as David Velleman (2005) points out, of family resemblance. We inherit our family history. We grow up with our parents and siblings. There is of course interpretation and direction in families, lots of it, but it tends to be guided and constrained by that same family history, family resemblances, and role relations within the family. ${ }^{\text {iii }}$ Identity within the family, therefore, tends to be more fixed than in friendships. I am the clever one, or the sporty one, the one who can be relied upon. This is usually - where the identity is positive - a good thing. Family relationships provide a necessary anchor for my agency - and a port to which I can return - whereas friendships (especially newer ones) can provide a space for exploration, for the trying on of new identities and new characteristics.

Given the importance of these close relationships to our self-understanding, self-concept, and sense of efficacy, loss or damage to a close relationship can affect our agency and identity in multiple ways. When we lose a close relationship, we may lose a sense of who we are, of our 
place in the world and our capacities to realise our plans and achieve our goals. There is no guarantee, for example, that others will see me as my family member or friend does. So, if our relationship founders, my view of myself as feisty rather than aggressive, or as having a subversive sense of humour rather than being simply obscure, may be lost and my identity will be less robust in the face of less charitable interpretations or the social invisibility that a stigmatised group membership may bestow.

We argue that in severe cases of addiction the addicted person's ability to play their part in the relationships just described may be quite limited; they may lose not one relationship but many, and so they are particularly vulnerable to the threats to identity, visibility, self-esteem and self-efficacy that the loss of relationships carry and to the imposition of a new addict identity.

How does addiction do this? Severe addiction is characterised by a narrowing of interests and attention to the pursuit and consumption of the drug of choice. Marc Lewis talks about the hourglass shape of addiction:

"They start out unique: each person begins with his or her own specific culture, family environment, level of education, personality, social network, personal secrets, and all the rest. But then, when addiction takes hold, these lives start to look exactly the same. Regardless of whether it's cocaine, opiates, alcohol, or even food, that wide range of individual differences shrinks to a narrow tube - the middle of the hourglass" (Lewis 2012).

In the middle of the hourglass, the addicted person is not (for the most part) directly responsive to others' interests or to their interpretations and has little to offer in return. They are impaired for forms of intimacy that require an interest in and capacity to focus upon the other person for their own sake, to undertake joint activities and develop joint interests. And they are unfit for family relationships that require fulfilling a certain role and abiding by the norms that govern the role - playing one's part as a son or daughter, sibling or parent. They are no longer the sporty one, or the reliable one, as previous interests and pursuits are lost. Moreover, this narrowing and rigidifying of interests is exacerbated when they treat their friends and families instrumentally, as a source of money or free shelter and food, and abuse their trust. When this happens repeatedly, loved ones typically respond to the addicted person with anger, blame and resentment. Ultimately they may move to the objective stance in order to protect themselves, and the individualized interpretations of personality, character and actions previously offered in their intimate relationships may be replaced by the stereotype of the addict. We now explore in more detail this process and its effects.

\section{The participant stance and the shaping of self-concept in addiction}

As noted above, in many (but obviously not all) cases of addiction, the addicted person treats their friends and family poorly, making unreasonable demands for money, stealing from them, breaking promises, and generally acting with disregard for their interests. They thus violate the most basic interpersonal expectation of goodwill as well as the relational expectations of particularised care and concern. Friends and family initially respond from within the participant stance with resentment and blame - holding the addicted person responsible for their actions. The addicted person also often exposes his family to negative reactive attitudes when they refuse his demands. 
'He would go to my mum 'shut up' and then it would get to the stage he would actually lose it, shout and bawl. If my mum went like that, 'right, just get out of the house' he would shout the whole way down the close [tenement stairwell]... and the whole way down the street he would be shouting 'ya fucking bitch' (Sibling, Martina)" (Barnard 2007, 32).

Typically, a feedback loop of resentment develops because family members resent being the target of the addicted person's unreasonable resentment. It is also common for the addicted person to seed resentment between other family members and then subsequently be resented for having had that effect on the family. ${ }^{\text {iv }}$

"I was very angry with them [his brothers and sisters], very resentful towards them. It works both ways because they become very resentful towards you. ... In harming himself he was effecting the whole family ... everyone's emotions are all shot up... (Parent: Ms Garvey)" (Barnard 2007, 29).

Eventually the addicted person's actions are suspected of being manipulative by default. The lack of trust severely limits the kinds of interactions the addicted person can have with their friends and family.

"It's always money, money, money. And I mean it makes me cringe when he puts his arm around me and he'll say 'I love you ma' and I push him away because I know it's not genuine... And it's terrible to do that with... But I can't help it. (Parent: Mrs Blain)" (Barnard 2007, 33).

When an embrace with one's mother is returned in kind, one usually becomes visible to oneself as someone who expresses love and is a worthy recipient of love. However, if the embrace is rejected, that makes one visible to oneself as someone who is not loved, someone who is manipulative and doesn't express love. ${ }^{\mathrm{v}}$

As the content of the addict's self-concept becomes entrenched, the addicted person begins to draw on it to frame her experience and her plans.

"I was worried about what other people were thinking about me and you know being an addict and ... I come from a good family and you know (...) I can fit in that group if I want to, but I know that I'm an addict (...) I think that they can see it, you know?" (Nicole). ${ }^{\text {vi }}$

Once one sees oneself as an addict, that self-concept more easily makes sense of experiences that fit with being an addict, e.g. others seeing one as an addict. Furthermore, plans that fit with being an addict make more sense so that recovery seems less achievable for someone like her. ${ }^{\text {vii }}$

Consistent negative reactive attitudes from others also erodes belief in the effectiveness of one's agency more generally and undermines self-efficacy.

"People's perception of me is so important now because I've ruined half of it. And I don't deny that that's my doing but to have them believe in me again is so important. And I can't even look at you in the eye 'cause I wonder if you think I'm even telling you the truth. This is how I feel ... I'm so scared that people are going to judge me that I don't know whether ... what I'm saying is worth it or not" (Diana). viii 
Diana exhibits low self-esteem (I don't know whether what I'm saying is worth it); a suspicion that she is seen as untrustworthy (I wonder if you think I'm telling the truth) which might belie a lack of self-trust; and a lack of self-respect (I can't look you in the eye). Such negative selfevaluations are reinforced by the negative attitudes directed at her by others and they are particularly detrimental because they undermine the self-authority needed for recovery and agency in general (Mackenzie 2014). Diana admits a role in ruining people's perceptions of her but that doesn't mean she can repair those perceptions on her own. In fact, she recognises that she needs others to 'believe in her again', to believe that she is worthy of some trust, respect, and esteem. If they do, they will help her to re-establish the self-authority she needs to direct her own recovery.

Exposure to negative reactive attitudes within the participant stance accelerates relationship difficulties as the addicted person is motivated to distance himself from negative reactive attitudes and the associated disvalued self-image.

"You start to use and you turn your back on everybody for fear of being caught. And then you just become so selfish about wanting to feel better rather than ... and so you turn on all your morals, all your principles and values, yeah" (Tom). ${ }^{\text {ix }}$

The addicted agent often feels intense shame and guilt because, between periods of intoxication, they are well aware that their behaviour conflicts with their values and those of the people in their close relationships (Flanagan 2013). Because our close relationships make us particularly visible to ourselves, participation in these relationships will tend to elicit shame and so the addicted person is motivated to withdraw from them.

Close friends and family can often see that guilt and shame are compounding the problems the addicted person faces. This recognition can motivate a different reactive attitude forgiveness. Forgiving involves "ceasing to have towards the wrongdoer the retributive reactive attitudes that her wrongdoing supports, without changing our judgments about the wrongness and culpability of her action. ... Forgiving makes sense when our concern is with giving them a chance to be different in the future" (Allais 2008, 20). Therefore, forgiveness should help alleviate guilt and support self-forgiveness which should help alleviate shame. Indeed, forgiveness and self-forgiveness do seem to be important for an ultimately successful recovery from addiction (Weaver, Turner, and O'Dell 2000). However, it seems that, typically, forgiveness is unhelpful when the other is still in the neck of the hourglass of addiction. By forgiving before the addicted person is ready to begin to "be different in the future", friends and family set the addicted person up for failure and fresh resentment. Families may thus cycle between forgiveness and resentment with it becoming progressively harder to forgive each time. Friends who lack the ties of obligation to the addicted person may simply end the relationship as the addicted person fails to engage in the mutual interpretation and shaping of interests and concerns that are constitutive of close friendship. In summary, close relationships become more distant as the non-addicted parties protect themselves from the destructive behaviour of the addicted person and the addicted person avoids the painful self-visibility provided by friends and family.

The addicted person's participation in their close relationships is often largely replaced by participation in relationships with drug-using acquaintances. This is partly pragmatic; these relationships help the agent secure and use drugs. However, many addicted people also report feeling more comfortable with these acquaintances. 
"The only time I feel comfortable is around other drug addicts and other people who are on substance because they accept [me] no matter what and I'm a pretty hard person to tolerate at times" (Julia). ${ }^{\mathrm{x}}$

We would expect these interactions to be more comfortable because they generate a less confronting self-visibility. Addicted people are less likely to expose each other to negative reactive attitudes for using drugs and they might be more sympathetic, understanding, resigned, or apathetic to behaviours that draw resentment in non-addicted circles. Despite being more comfortable, however, these relationships often lack an important defining feature of close friendship: participants in these relationships are not usually open to shaping each other in ways outside of their shared interest in securing and using drugs. Indeed, people trying to cease using drugs often report negative feedback from their drug using acquaintances.

“The other addicts aren't really...they don't want to see someone get on with their life 'cause then... oh this is what I think, then...it's saying to them, maybe you can do this but they don't want to...they're comfortable....'cause I notice when I'm going well, no-one's that happy and it's like no-one wants to give you a shot when you're hanging out but when you've been clean for six months everyone wants to give you a shot" (John). ${ }^{\mathrm{xi}}$

\section{A shift to the objective stance}

When an addicted person displays consistent disregard for herself and others despite resentment or forgiveness this appears to make her an appropriate target of the objective stance, i.e. as someone to be managed, handled, cured, trained or simple avoided. We certainly see examples of people taking the objective stance to addicted people:

"Oh I know the person that's using the drugs is not the son I had, I understand that, that's a shell of the person I knew... I mean all I see is an addict, I don't see my son anymore because I know that's not my son, definitely isn't my son"' (Parent: Mr Bell) (Barnard 2007, 50).

The effect of such invisibility and exclusion from social interaction on the agent's self-authority is particularly severe.

"You're a drug addict person. People look to you ... a different way ... they judge you, they're scared of you, lots of things. Different from ... normal people. ... You're really low, you're just like nobody" (Hien). ${ }^{\text {ii }}$

Indeed, as Strawson recognises, taking the objective stance for too long is incompatible with human interactions. "Being human, we cannot, in the normal case, do this for long, or altogether. If the strains of involvement, say, continue to be too great, then we have to do something else like severing a relationship" (Strawson 2008, 10). So the objective stance too, leads to a breakdown of the relationship and certainly to a loss of the intimacy and security that close relationships provide.

Moreover, the objective stance may be based upon and nurture the belief that the outcomes of addiction will be determined by something that is independent of the efforts of the 
addicted person. ${ }^{\text {xiii }}$ If addiction is seen, for example, as an illness or a disease, the progress of which is outside the voluntary control of the addicted person then friends, family and the addicted person themselves should defer to the experts on treatment and management of the condition. . Such a view of addiction can provide relief to all parties from painful blame and shame but it comes at a cost both to the relationships and to recovery. In taking the objective attitude, the addicted person's behaviour may be viewed entirely mechanistically - as caused by forces external to their agency to which they are largely helpless onlookers. But if recovery actually requires at least some effort from the addicted person (Pickard 2012), the objective stance might compound addiction by discouraging significant others from both the belief that such efforts can be effective and or that the addicted person is capable of making them. This leads to a sense of fatalism in their attitude towards the addicted person as they give up on the prospects of re-engagement and recovery. While they may continue to love their friend or family member they step back from more active forms of engagement.

"I'd be very surprised if any of my boys get through this, now, the two that's using. I think the best I can hope for is burying them... I don't think they'll get through this, you know, it's been too long now"(Parent: Mr Merrick) (Barnard 2007, 50).

Similarly, addicted persons frequently end up adopting a resigned and fatalistic stance towards their lives and their addiction. (Kennett 2013) Repeated experiences of failure to live up to their obligations, of other's disappointment and anger with them, and their own shame at their behaviour, results in a loss of confidence in their ability to exert control over their circumstances, to play their part, and to shape the lives they would value having and the people they would value being. They become onlookers rather than participants in their own lives, sharing others' bleak assessments of the likely outcome of their addiction. We can see evidence of addicted people internalising the objective stance in the fatalistic stories they tell about their pasts and futures. When asked where he saw himself in one year's time, one study participant said, "Probably exactly where I am now. Exactly where I am now." (Howard). Another respondent said:

"When I'm in the throes of addiction and I'm trying to stop and I can't stop, my head's going this is who you are. I can accept that you know what I mean. That's ... as weird as that sounds I can accept that I'm a junkie. I'm ... my life is over and this is what I'll be until I die. It's the only way I can stop is to die" (Dan). ${ }^{\text {xiv }}$

\section{A modified stance: rebuilding relationships and resolving the dichotomy}

For the addicted person, the participant and objective stances present a detrimental dichotomy that makes maintaining relationships difficult and recovery less likely. The participant stance as laid out by Strawson demands a level of responsiveness to others and responsibility in discharging obligations that is beyond that which the addicted person can consistently achieve. Conversely, the objective stance assumes the other lacks the capacities needed to play their part in inter-personal relationships tout court, when, for the most part, addicted people retain this capacity to a significant extent. As Jennifer Radden notes, it is cruel and unjust to treat someone as having more autonomy than they do but, equally, to treat them as having less than they do 
(2002, 399). The above discussion has explained how both injustices have compounding, detrimental effects.

The mistake has been to think that engagement from within the participant stance must presume and require equal responsibility and capacity of the parties or else it is somehow defective (Kennett 2007). This is not how human relationships (or human-animal relationships) work. It is possible to navigate a middle path where one participates with the other in a way that is sensitive to their present capacities for engagement and responsiveness and so keeps the door of the relationship open to both parties. There are a multitude of valued ways in which we can, and ordinarily do, engage with and shape each other that don't depend on particularly high levels of autonomy or moral responsibility. I can value your appreciation of slap-stick, your melodramatic involvement in watching your sports team, your ironic commitment to a brand of beer, your clumsiness, your warmth, your laugh, your particular facial expressions. None of these things depend strongly on the kinds of developed agential capacities that underwrite and justify the reactive attitudes of indignation and blame with which we began our discussion. We commonly adjust our responses and expectations in the light of facts about the other, their sensitivities, capacities, and so on, without abandoning the participant stance. A father for example chooses a slap-stick comedy rather than a political satire to watch because he is tailoring the activity to his son. He chooses something they can enjoy together and there is nothing defective about such a choice or such an interaction. Even among friends at the bar a similar thing can happen: if the conversation happens to drift into one person's area of expertise she doesn't hold her friends to the same standards as her colleagues (and her friends might only have a partial grasp of the way she is holding back).

In addiction-affected relationships, the potential for mutual shaping and responsiveness can often be improved by choosing (and limiting) times for interaction to when the addicted person is neither intoxicated or craving and by selecting activities that will highlight the positive aspects of their character and be mutually enjoyable. Perhaps mention of drug policy will set my friend off on a rant about his mistreatment by the state and, I suspect, this shifting of responsibility and associated self-pity is unhelpful in his recovery. Better to watch a movie that appeals to our shared sense of humour or shoot a few hoops in the backyard. Families and friends can try to scaffold experiences that maintain narrative threads with the pre-addicted self, draw upon retained skills and capacities, and connect to different possible futures, even while recognising the addicted person's currently limited capacity for reciprocity. Where they do succeed in sharing a pleasant meal, a cup of coffee or half an hour shooting hoops that can be enough for that time. Each positive interaction provides positive visibility for the addicted person. In that moment they can see themselves as holding up their end of the relationship, as valued, and as loved.

Despite efforts to tailor the scope of the interaction appropriately, the addicted person might still sometimes act in blameworthy ways, particularly when they are in the neck of the hourglass of addiction. Furthermore, even when they have emerged from this phase and are seeking paths to recovery there is likely to be a history of blameworthy events that haven't yet been fully resolved. In response, the non-addicted person can be tempted back towards either pole of the dichotomy. The objective stance would relieve them from the effort of resenting and may justify (or rationalise) withdrawal from the relationship. The participant stance appeals because it defends one's own value as someone who deserves goodwill. It also communicates the hope that the other could be better and, outside of addiction, this pressure often works. Unfortunately, for those suffering from addiction it often asks too much of them too soon. . 
In the face of blameworthy behaviour, perhaps we can modify the participant stance so that we communicate the breach of our expectations but without the negative effects of the usual reactive attitudes surrounding blame. This seems to be the approach that Hanna Pickard (2017) suggests when she distinguishes affective blame from our practices of judging and holding others responsible for their actions. Affective blame is the normal response in the participant stance and involves resentment. In practices of responsibility without blame, however, resentment is suspended, but the addicted person is still held to be accountable for their actions and explicitly seen as capable of doing better. This, Pickard argues, is essential to recovery since the addict must also see themselves as the agent of their own recovery.

\section{Conclusion}

The dynamic between an addicted person and their friends and family is often an important contributor to the chronicity of addiction. Friends and family take the participant stance by default and expose the addicted person to consistent resentment. As a result, the addicted person suffers from guilt and shame and becomes visible to himself as a drug-user who deliberately treats others with ill will. As he internalises this self-concept, although he maintains his status as a person capable of moral responsibility, he sees himself as a bad person who is undeserving of a better life and for whom continued drug-use makes more sense than recovery.

The addicted person's consistent irresponsiveness (if not insensitivity) to reactive blame and resentment may then lead friends and family to take the objective stance, treating the addicted person as a problem to be managed. This undermines the addicted person's status as a moral equal and encourages him to develop a fatalistic self-concept at odds with any exercise of agency including that required for recovery. Both participant and objective stances encourage a mutual withdrawal from close relationships which tends to leave the addicted person with just their drug-using relationships. This unbalanced social environment provides few opportunities to develop and maintain the variety of non-drug-using identities and capacities necessary for recovery.

However, we are neither forced nor normatively required to choose between the full participant stance or the objective stance in our dealings with addicted people. Not all valuable intimate relations need to presuppose full autonomous agency and we have argued that it is possible to establish or maintain areas of genuine reciprocity with persons whose agency and social responsiveness is underdeveloped, impaired, or intermittent. This is a worthwhile endeavour for families and friends of addicted persons that supports the addicted person's agency and self-concept while providing some protection from the worst impacts of a loved one's addiction. 


\section{References}

Allais, L. (2008) "Dissolving reactive attitudes: Forgiving and understanding", South African Journal of Philosophy 27(3): 179-200. doi:10.4314/sajpem.v27i3.31511.

Barnard, M. (2007) Drug Addiction and Families, London: Jessica Kingsley Publishers. Branden, N. (1993) "Love and psychological visibility", in Badhwar, N. K (ed), Friendship, A Psychological Visibility, Ithaca: Cornell University Press, pp. 65-72.

Cocking, D., and Kennett, J. (1998) "Friendship and the self", Ethics 108(3): 502. doi:10.1086/233824.

Flanagan, O. (2013) "The shame of addiction", Frontiers in Psychiatry 4(OCT): 1-11. doi:10.3389/fpsyt.2013.00120.

Kennett J. (2007) "Mental disorder, moral agency and the self" in B. Steinbok (ed), The Oxford Handbook of Bioethics, Oxford, UK: Oxford University Press, pp. 90-113

Kennett J. (2013) "'Just say no? Addiction and the elements of self-control"”, in N. Levy (ed), Addiction and Self-Control, Oxford, UK: Oxford University Press

Lewis, M. (2012) "The hourglass shape of addiction and recovery", in Understanding Addiction: A New Perspective Linking Brain, Behaviour, and Biography, [city: Publisher]. http://www.memoirsofanaddictedbrain.com/connect/the-hourglass-shape-of-addiction-andrecovery-2/.

Mackenzie, C. (2014) "Three dimensions of autonomy: A relational analysis", in Autonomy, Oppression, and Gender, New York: Oxford University Press, pp. 15-41.

McConnell, D. (2016) "Narrative self-constitution in the context of addiction", American Philosophical Quarterly 53(3): 307-22.

Pickard, H. (2012) "The purpose in chronic addiction", AJOB Neuroscience 3(2): 40-49.

Pickard, H. (2017) "Responsibility without blame for addiction”, Neuroethics 10(1): 169-180. doi:10.1007/s12152-016-9295-2.

Radden, J. (2002) "Psychiatric ethics". Bioethics 16(5): 397-411.

Strawson, P. (2008) Freedom and Resentment and Other Essays, London: Routledge.

Todd, P. (2016) "Strawson, moral responsibility, and the 'order of explanation': An intervention", Ethics 127(1): 208-240.

Velleman, D. J. (2005) "Family history”, Philosophical Papers 34(3): 357-378.

Weaver, G. D., Turner, N. H. and O'Dell, K. J. (2000) "Depressive symptoms, stress, and coping among women recovering from addiction", Journal of Substance Abuse Treatment 18(2): 161-167. doi:10.1016/S0740-5472(99)00031-8.

\footnotetext{
${ }^{\mathrm{i}}$ There is a considerable debate about the order of explanation in Strawson (See Todd 2016). Is responsibility constituted by our actual practices of praise and blame or are these practices appropriately constrained by features of the agent themselves? We assume the latter for the purposes of this chapter.

ii Of course, the interpretations provided by friends and family are not always more accurate than that of others. Friends and family can develop set views of a person rooted in their shared history so that their interpretations are less responsive to changes in the agent. Similarly, friends and family may be more prone to collude with a person's false self-image because they want to support her. Those less involved with the agent will be less affected by these sources of bias;
} 
however, the relatively narrow, less intimate nature of their interactions with the agent prevents their interpretations from having a particularly pervasive influence on the agent's self-concept.

iii Long-running friendships also exhibit these characteristics to some extent because, here too, the shared history constrains how the other is prepared to see us. There may not be therefore, such a sharp distinction between family relationships and longer-running friendships. However, familial relationships involve the longest shared histories (often from birth) and are influenced by family traditions and expectations that predate one's birth. So, identities within the family are typically less malleable than in even our longest friendships.

iv The addicted person may also be resented for harming the family's reputation. The family becomes the target of stigma. "It is [shameful]... because some of the times she's went in and she's stole other people's kids toys and they come up and say 'She stole out the house.' And you go out and you feel it, you see the heads going and maybe you'll walk up and they're going on 'Aw see these f'ing junkies. The bane of our life.' (Parent: Ms Nugent)" (Barnard 2007, 30).

${ }^{v}$ It might even suggest a self-concept of being unlovable and incapable of expressing love. That, more serious, psychological move is indicative of the objective stance as we explain below.

${ }^{v i}$ From interviews conducted by Anke Snoek for the Australian Research Council funded Project: Addiction and Moral Identity

vii For a detailed discussion of this phenomenon see McConnell (2016).

viii From interviews conducted by Anke Snoek for the Australian Research Council funded Project: Addiction and Moral Identity

ix From interviews conducted by Anke Snoek for the Australian Research Council funded Project: Addiction and Moral Identity

${ }^{x}$ From interviews conducted by Anke Snoek for the Australian Research Council funded Project: Addiction and Moral Identity

${ }^{x i}$ From interviews conducted by Anke Snoek for the Australian Research Council funded Project: Addiction and Moral Identity

xii From interviews conducted by Anke Snoek for the Australian Research Council funded Project: Addiction and Moral Identity

xiii In most cases, it is clear that the addicted person desires to recover and so his failure to consistently respond to the reactive attitudes may be seen by him and others as evidence that he lacks the agential capacity, not that he refuses to use that capacity.

xiv From interviews conducted by Anke Snoek for the Australian Research Council funded Project: Addiction and Moral Identity 